\title{
Os reflexos socioeconômicos do Programa de Aquisição de Alimentos: Assentamento Agrovila Vila Formosa - Dourados/MS
}

\author{
Adáuto de Oliveira Souza \\ Universidade Federal da Grande Dourados - Dourados - Mato Grosso do Sul - \\ Brasil \\ ORCID: https://orcid.org/0000-0002-9396-8154 \\ Allison Cesar Martins Souza \\ Universidade Federal da Grande Dourados - Dourados - Mato Grosso do Sul - \\ Brasil \\ ORCID: https://orcid.org/0000-0003-1972-6736

\section{Gabrielli do Carmo Martinelli} \\ Universidade Federal da Grande Dourados - Dourados - Mato Grosso do Sul - \\ Brasil \\ ORCID: https://orcid.org/0000-0001-9240-240X
}

\section{Resumo}

O presente artigo tem como objetivo analisar os efeitos do Programa de Aquisição de Alimentos (PAA) no assentamento da Agrovila Vila Formosa de 2010 a 2015. Fundamenta-se em um estudo de caso apoiado em questionários e entrevistas semiestruturadas realizadas no assentamento Agrovila, localizado no município de Dourados, estado de Mato Grosso do Sul. Ao analisar os reflexos socioeconômicos ao longo de cinco anos observa-se que o PAA ofertou contributos que atendem as necessidades básicas alimentares de pessoas carentes na sociedade brasileira, inclusive na cidade de Dourados-MS. Além disso, valoriza a produção e a cultura alimentar das populações, dinamizando a economia local, a formação de estoques estratégicos, a melhoria da qualidade dos produtos da agricultura familiar, o incentivo ao manejo agroecológico dos sistemas produtivos e ao resgate e preservação da biodiversidade.

Palavras-chave: Desenvolvimento local. Política pública. Segurança alimentar.

The socioeconomic reflections of the food acquisition program: agrovila village settlement formosa - Dourados/MS

\section{Abstract}

This article aims to analyze the effects of the Food Acquisition Program in the settlement of Agrovila Vila Formosa from 2010 to 2015. It is based on a case study based on questionnaires and semi-structured interviews conducted in the Agrovila settlement located in the municipality of Dourados state of Mato Grosso do Sul. Analyzing the socioeconomic 
repercussions over five years, the Food Acquisition Program offered contributions that meet the basic food needs of the needy in Brazilian society, including in the city of Dourados-MS. In addition, it values the production and food culture of the populations, boosting the local economy, building strategic stocks, improving the quality of family farming products, encouraging the agro-ecological management of productive systems and the rescue and preservation of biodiversity.

Keywords: Local development. Public policy. Food security.

Los reflexos socioeconómicos del programa de adquisición de alimentos: asentamiento agraria villa formosa - Dourados / MS

\section{Resumen}

El presente artículo tiene como objetivo analizar los efectos del Programa de Adquisición de Alimentos (PAA) en el asentamiento de Agrovila Vila Formosa de 2010 a 2015. Se fundamenta en un estudio de caso apoyado en cuestionarios y entrevistas semiestructuradas realizadas en el asentamiento Agrovila, en el municipio de Dourados, estado de Mato Grosso do Sul. Al analizar los reflejos socioeconómicos a lo largo de cinco años se observa que el PAA ofreció contribuciones que atienden las necesidades básicas alimentarias de personas carentes en la sociedad brasileña, incluso en la ciudad de Dourados-MS. Que se ha convertido en una de las más importantes de la industria agropecuaria, que se ha convertido en una de las más importantes de la industria agroalimentaria.

Palabras clave: Desarrollo local. Política pública. Seguridad alimentaria.

\section{Introdução}

A agricultura familiar vem se fortalecendo no Brasil, notadamente a partir do início do século XXI, por meio da criação de políticas públicas e linhas creditícias como o Programa de Aquisição de Alimentos (PAA), quando ocorreu um contributo para o desenvolvimento de pequenas propriedades rurais, além de promover a segurança alimentar e alimentação básica, ainda incentiva o agricultor familiar desde a concepção de instrumentos que apoiam a produção até a comercialização (CONAB, 2012).

Tanto é, que o agricultor familiar é responsável pela produção de $70 \%$ dos alimentos básicos consumidos pelos brasileiros, sua elevada produção incentiva o governo federal a investir seus recursos em linhas contra a miséria, fome e desigualdades sociais no país (BRASIL, 2017). Sendo primordial manter essas políticas públicas que beneficiem os agricultores familiares, uma vez que para as gerações futuras o crescimento populacional demandará um aumento por alimentos, em que será necessário produzir cerca de $60 \%$ a mais do que se produz hoje até 2050 (FAO, 2016).

Nesse contexto, em 2003, o PAA surge sob a proposta de consolidar alicerces nas aquisições institucionais de produtos pela agricultura familiar. Com tais pressupostos o Programa fortalece as organizações de produtores rurais e atua no desenvolvimento de um processo sustentável (ALTIERI et al., 2012; MACIEL; FLECH, 2011).

Assim, com o intuito de enfrentar a fome e a pobreza nacional, o Governo Federal cria o PAA, buscando o fortalecimento da agricultura familiar. Para tanto, utiliza estratégias que agreguem valor à produção, sendo um dos mecanismos a 
comercialização direta dos produtos, favorecendo assim a aquisição dos produtos do pequeno agricultor ou de suas organizações, visando de forma estrutural e organizacional, estimular as pequenas propriedades a se fortalecerem na produção e comercialização de seus produtos no mercado (MDA, 2014).

Neste sentido, o PAA busca a articulação com o mercado consumidor, proporcionando o crescimento/fortalecimento da agricultura familiar, priorizando as modalidades políticas que auxiliam e facilitem a produção e a comercialização de alimentos básicos. Ela tende à proporcionar maior estabilidade e melhoria de vida aos agricultores familiares, assim como favorecer no Programa Nacional de Fortalecimento da Agricultura Familiar (PRONAF), através da compra sem licitação de produtos agrícolas (GAZOLLA; SCHNEIDER, 2013).

É notório que uma das maiores dificuldades do pequeno produtor familiar é inserir seu produto em circulação, principalmente nas grandes redes atacadistas que exigem regularidade na entrega dos produtos, o que nem sempre é possível atender, até em função das condições climáticas e técnicas que o este agricultor se submete (DEVES; RAMBO, 2013). Portanto, inserir a figura do agricultor familiar nesse processo de comercialização da produção da agricultura familiar é fundamental para que as famílias com pequenas parcelas de terras permaneçam assentadas na zona rural através da comercialização de sua produção familiar (CARVALHO; NETO, 2016).

Assim, o PAA sendo uma política pública governamental, preenche essa lacuna, buscando dinamizar a economia dos agricultores familiares, incentivando a mão de obra familiar e a valorização dos produtos para a comercialização. De acordo com Silvestre et al., (2005), a produção em conjunto atrelado ao cooperativismo é uma política que visa um modelo socioeconômico coabitando o bem-estar e o desenvolvimento econômico, caso utilizada adequadamente por produtores rurais que fazem parte de um cluster, seja uma associação ou uma cooperativa podem minimizar, dificuldades como: circulação de mercadorias, compra de insumos entre outros.

Segundo Grisa et al., (2011), o PAA busca restaurar a diversidade na produção, tentando diminuir a tradicional monocultura influenciada pelos avanços tecnológicos e por históricos incentivos governamentais decorrentes inclusive da chamada "Revolução Verde". Determinante, por exemplo, pelo processo de modernização da agricultura, processo intensivo de produção que nos últimos 25 anos tem ocasionado a queda no rendimento produtivo, pois $30 \%$ das terras agricultáveis sofreram declínio na qualidade e produtividade do solo, e ainda são responsáveis por 24\% das emissões de Gases de Efeito Estufa, quando considerado o contexto mundial (FAO, 2017; FOLEY et al., 2011; SMITH et al., 2014).

Assim, o crescimento da policultura tende a minimizar os impactos ambientais e valorizar os produtos locais como frutas, verduras, produtos de origem animal e agroindustrializados, tornando atrativo para o pequeno produtor rural, até porque o desenvolvimento rural busca ferramentas para incentivar o crescimento socioeconômico, tornando um processo influente na produção (VELOSO, 2017). Portanto, os assentamentos podem promover ao produtor melhores condições de vida, por se tratar de uma extensão de terra divididas independentemente entre si, constituindo pequenas propriedades rurais, além de contém infraestrutura básica em cada lote, permitindo que esse público atenda aos 
requisitos exigidos para fazer parte do PAA. Sendo requisitos: ser agricultor familiar, assentado, extrativistas, silvicultores, indígenas entre outros que se enquadrem na Lei $\mathrm{N}^{0} 11.326 / 2006$ e no Decreto $n^{0} 7.775 / 2012$ (CASTILHOS et al., 2001; CONAB, 2017).

Portanto, os produtores familiares são protagonistas neste processo de diminuição de disparidades regionais através da produção, comercialização e distribuição de seus produtos oriundos da mão-de-obra assentada no campo, fazendo com que essa população se mantenha ocupada no campo. Afim de produzir alimentos para abastecer as populações mais carentes nas cidades (HESPANHOL, 2013; COLNAGO; HESPANHOL, 2017; NAKUJA; KERR, 2018).

A partir de então surge o seguinte questionamento: Com o surgimento do PAA o assentamento da Agrovila Vila Formosa, localizado no município de Dourados, agregou benefícios fomentando o crescimento em sua produção e contribuindo para uma melhor satisfação financeira e pessoal? Esse questionamento impulsionou a pesquisa, pois a partir da leitura sobre a temática e pesquisa empírica, fica evidente a figura do agricultor familiar, já que o mesmo se torna protagonista em decorrência da produção ser oriunda da agricultura familiar. O governo federal também possui um papel fundamental no desenvolvimento local das famílias participantes do programa, pois a destinação de recurso por meio de política pública pode incentivar os produtores, em especial nesse estudo, os assentados a continuarem no campo.

Diante deste contexto, o objetivo geral deste estudo é analisar os efeitos do Programa de Aquisição de Alimentos no assentamento da Agrovila Vila Formosa de 2010 a 2015. Os participantes do PAA do assentamento Agrovila Vila Formosa reúnem agricultores familiares do distrito, sendo a associação denominada de AGROFORM, conta com a parceria do SESC/Dourados, através do programa "Mesa Brasil”, que auxilia na identificação das entidades (assistenciais, filantrópicas etc.) a serem beneficiadas na cidade. São 77 entidades beneficiadas, sendo atendidas mais de 34 mil pessoas.

Como procedimentos de pesquisa buscou-se por meio de revisão bibliográfica, estudos já realizados na área, como base para execução do referencial teórico. A área delimitada para a análise foi a Agrovila da Vila Formosa. Quanto aos meios de investigação, a técnica de coleta de dados será para a definição da pesquisa de modo descritivo, levantamento de campo com aplicação de questionários e entrevistas semiestruturadas aos assentados da Agrovila, no qual compreende um montante total de 35 famílias para a análise.

\section{Programa de Aquisição de Alimentos - PAA}

O PAA foi criado em 02 de julho de 2003 por meio da Lei nº 10.696 na esfera do Programa Fome Zero, em que objetivava incentivar a agricultura familiar e promover a alimentação mínima possível para a sobrevivência dos indivíduos. Uma das vantagens do programa é a compra direta da produção, através de compras governamentais dos alimentos. Ainda, valoriza a biodiversidade da produção contribuindo com a diversidade, aumentando os recursos naturais, por não utilizar a terra intensivamente, favorecendo os fatores bióticos e abióticos do meio ambiente (MDA, 2012). 
Esse programa constitui cinco modalidades como: Compra da Agricultura Familiar para Doação Simultânea; Formação de Estoques pela Agricultura Familiar CPR Estoque; Compra Direta da Agricultura Familiar - CDAF; Incentivo à Produção e Incentivo de Leite - PAA Leite e Compra Institucional, sendo que os limites dos recursos variam de quatro a oito mil reais por mutuário. Para tanto, dentre as cinco modalidades, duas destas, a Compra Institucional e a Formação de Estoques pela Agricultura Familiar, obrigam o produtor que deseja participar destas associar-se a cooperativas ou associações, caso isso não seja contemplando o mesmo fica vetado (MDA, 2015).

Por meio o relatório geral da CONAB, (2017) é possível observar que desde 2003 até 2016 houve uma queda dos recursos aplicados para a aquisição de produtos oriundos do PAA, em 13 anos a Região Centro-Oeste foi a que menos investiu em relação as outras quatro, totalizando $\mathrm{R} \$ 261.751 .844$, ainda nota-se que também ocorreu uma queda desses recursos quando comparados os anos de $2015 \mathrm{e}$ 2016, o investimento diminuiu em 89.938 .498 considerando as cinco regióes do Brasil.

Infelizmente, a fome no mundo também tem aumentado ao longo dos anos, a Food and Agriculture Organization of the United Nations (FAO) divulgou em seu relatório que no ano de 2017 são 815 bilhões de pessoas que passam fome, isso corresponde um total de $11 \%$ da população mundial. Com isso, vários trabalhos continuam sendo elaborados com assuntos vinculados ao PAA, que por sinal possui a finalidade de sanar a fome da população.

A abordagem do PAA tem-se disseminado por diversas cidades do Brasil, como em Roraima, Rio Grande do Norte, São Paulo, Rio Grande do Sul, Rondônia, Minas Gerais, Paraná, Mato Grosso do Sul nos últimos 6 anos. Como por exemplo Rocha e Anjos, (2016) analisaram quais foram os efeitos, tanto negativos como positivos após a implantação do PAA na cidade de Boa-Vista estado de Roraima. Enquanto que Dias et al., (2013) elaboraram um trabalho objetivando analisar o PAA como estratégia de inserção socioeconômica, por meio de um estudo de caso no Território da Cidadania Sertão do Apodi (Rio Grande do Norte), com intuito de verificar a influência que a organização detém no processo de comercialização dos produtos via PAA.

Para tanto, notou-se que a inserção do produtor rural em uma organização ou associação facilita o processo de destinação final dos produtos, porém observase que ainda existem dificuldades para enquadrar-se no programa, pois a comercialização de subprodutos necessita de certificações, e isso acaba burocratizando a destinação final desses.

Já Souza-Esquerdo e Bergamasco (2014) verificaram a importância de políticas públicas como o PAA em prol da valorização do agricultor familiar no estado de São Paulo, no entanto percebeu-se que é pequena a participação dos agricultores nesses programas. Segundo o INCRA (2015), apenas 139 assentamentos utilizam o PAA para a comercialização direta dos produtos neste estado. Ainda em São Paulo um estudo elaborado no assentamento situado na região do Pontal do Paranapanema, concluiu-se que as inclusões dos assentados no Programa proporcionaram bem-estar e melhores condições alimentares, atingindo a classe 
vulnerável local, além de aumentar a renda e promover segurança ao produtor rural (MARQUES et al., 2014).

Grisa, (2010) enfatiza como o desenvolvimento local é influenciado pelas relações de poder. A criação de políticas públicas indica um conjunto de decisões políticas que determinam seus objetivos, limites e estruturas de poder. Nos últimos anos, a agricultura familiar brasileira obteve-se um desempenho positivo, principalmente devido ao fomento de políticas públicas, por exemplo em Rondônia foram aplicados recursos financeiros destinados a intensificação do PAA, que valorizaram os produtos agrícolas por pagarem preços justos, afim de aproximar o produtor e o consumidor (VALNIER; RICCI, 2013).

Em Minas Gerais, o foco do trabalho de D’Ávila; Silva, (2011) foi sobre a segurança alimentar e o desenvolvimento local, tendo como objetivo analisar a percepção dos atores sociais que compõem o seu arranjo institucional. A metodologia utilizada foi uma análise de literatura, com auxílio de entrevista semiestruturada e visita in loco. Os relatos dos entrevistados permitem destacar a evidencia na qualidade dos produtos recebidos, melhoria dos índices nutricionais dos consumidores, mudanças de hábitos alimentares devido a diversificação de produtos, e a valorização do mercado local e regional. Também no estado do Paraná o foco é a influência do programa na sustentabilidade e diversidade da produção, logo os resultados também se mostram satisfatórios (MIRANDA; GOMES, 2017).

Por fim, no estado de Mato Grosso do Sul, Heling et al., (2017) tem por objetivo investigar a atuação operacional do PAA entre 2012 à 2017, particularmente no tocante ao orçamento anual do programa, avanços, limites e desafios, após a análise dos dados secundários verificou-se que houve uma queda nos últimos cinco anos dos recursos disponibilizados no investimento do programa, fazendo com que ocorra limitações para a permanência do produtor na zona rural, pois a renda desses agricultores é provinda principalmente da venda de produtos agrícolas.

\section{Agricultura familiar}

No ano de 2015, no período de recessão em que se encontrava a economia no Brasil, os setores como serviços e indústria foram os mais afetados nesse cenário desfavorável (MDA, 2015). Porém, o setor agropecuário, especialmente a agricultura familiar, obteve um desempenho satisfatório, assim como as perspectivas para 2016/2017 (CONAB, 2016).

O setor agropecuário foi o menos afetado pela crise. De acordo com dados divulgados pela CONAB (2015), ocorreu um aumento na safra, em janeiro de 2015, sendo a produção de 210.475,9 milhões de toneladas referentes a safra 2015/2016, ultrapassando em 1,4\% em relação à safra anterior. Ainda, no ano de 2017 O PIB aumentou $1 \%$ quando comparado com a ano de 2016, sendo o agronegócio responsável por 0,7\% deste percentual total (IBGE, 2017).

Esses dados evidenciam a influência significativa que o setor possui quanto ao crescimento do Produto Interno Bruto (PIB) do país. No Brasil, o agronegócio beneficia os produtores rurais, reunindo atividades com fornecimento de bens e serviços à agricultura, produção agropecuária, processamento, transformação e distribuição de produtos de origem agropecuária até o consumidor final, 
caracterizando o agronegócio como moderno, eficiente e competitivo (MAPA, 2015). Essas três características se tornam evidentes com a tecnificação dos manejos de produção, rendimento produtivo aumentado, no entanto, por meio da intensificação sustentável, isso em decorrência a agricultura de precisão. Hoje a eficiência da produção não está pautada na abertura de novas áreas, mas sim, no aumento da produção por meio de manejos agrícolas sustentáveis (MOTTALEB, 2018; KUMAR et al., 2018; BARNES et al., 2019).

A agricultura familiar vem acentuando-se no Brasil, impulsionando a economia local e reduzindo o nível de pobreza. Esse crescimento contribui para o fomento da produção da alimentação básica, propagando assim, o desenvolvimento das pequenas propriedades rurais. Além disso, é incumbida, por gerar emprego, renda, no entanto os agricultores familiares detêm de apenas 20\% das terras agricultáveis no Brasil, mas ainda é a classe que mais contribui para abastecer a mesa da população (AQUINO et al., 2018). O governo federal, por meio de políticas públicas, cria programas como PAA, O Programa Nacional de Alimentação Escolar (PNAE) e a Política de Garantia de Preços Mínimos (PGPM) que incentivam a agricultura familiar, desde a criação de instrumentos de apoio a produção até a comercialização, priorizando o desenvolvimento local e regional.

A lei ordinária $n^{0} 11.326 / 06$ foi criada para definir o conceito de agricultura familiar no Brasil, a extensão de terra varia de um a quatro módulos fiscais, a mão de obra para a produção deve ser familiar no estabelecimento ou empreendimento, a renda precisa ser gerada através do fruto do cultivo do estabelecimento. De acordo com Barcelos e Reis (2014), a agricultura familiar é responsável pela diminuição do êxodo rural, ajudando ativamente na geração de riqueza não somente no setor agropecuário mais também do país como um todo. Na Tabela 1 demonstra-se o número de estabelecimentos e área (ha) de agricultura familiar que existem no Brasil e na região do Centro-Oeste.

Tabela 1. Quantidade de estabelecimentos e área por hectare correspondente a agricultura familiar existente no Brasil, região Centro-Oeste e estado de Mato Grosso do Sul

\begin{tabular}{lcc}
\hline & Estabelecimentos & Área \\
País, região e município & Agricultura familiar & Agricultura familiar \\
\hline Brasil & 4.367 .902 & 80.250 .453 \\
Centro - Oeste & 217.531 & 9.414 .915 \\
Mato Grosso do Sul & 41.104 & 1.190 .206 \\
\hline
\end{tabular}
Fonte: IBGE, 2006.

Quando os dados são comparados com os outros estados do Brasil, observase com base no Censo Agropecuário 2006, que na região do Centro-Oeste a agricultura familiar representa $4,98 \%$ do total de estabelecimentos da agricultura familiar do país, e o estado de Mato Grosso do Sul configura 63,30\% do total da região Centro-Oeste. Sendo que, uma considerável parcela desses agricultores familiares mora em assentamentos.

Na Tabela 2 ilustra-se o número de assentamentos por país, região e estado. Dentre as 5 regiões do Brasil o Centro-Oeste encontra-se na terceira posição em números de assentamentos. Esses dados evidenciam o papel da agricultura familiar 
no crescimento da população rural e contribui com o crescimento econômico da região.

Tabela 2. Agricultores familiares assentados por país, região e estado.

\begin{tabular}{l|ccc}
\hline Local & $\mathrm{N}^{\circ}$ de famílias & & \\
assentadas & $\mathrm{N}^{\circ}$ de assentamentos & Área de assentamentos (ha) \\
\cline { 1 - 3 } Brasil & 972.289 & 9.374 & $87.978 .041,18$ \\
\cline { 1 - 1 } Centro-Oeste & 135.867 & 1268 & $7.991 .819,19$ \\
\cline { 1 - 1 } Mato Grosso do Sul & 27.764 & 204 & $716.212,19$ \\
\hline
\end{tabular}

Fonte: INCRA, 2017.

\section{Metodologia}

O estudo foi desenvolvido no Assentamento Agrovila Vila Formosa, localizado no município de Dourados (MS) (Figura 1). O município é parte integrante da Mesorregião do Sudoeste de Mato Grosso do Sul e da Microrregião de Dourados com população total de 196.035 habitantes em que ocupa uma unidade territorial de 4.086,24 (km²) (IBGE, 2010).

O assentamento Agrovila Vila Formosa foi criado em 1999 sendo o primeiro voltado a produção de hortifrutigranjeiro no município de Dourados - MS. Composto por 46 lotes com dimensão de 2,5 hectares. Cada lote contempla uma casa de alvenaria de 32,9 $\mathrm{m}^{2}$ e infraestrutura básica.

Figura 1. Localização do município de Dourados e do Assentamento Agrovila Vila

Formosa

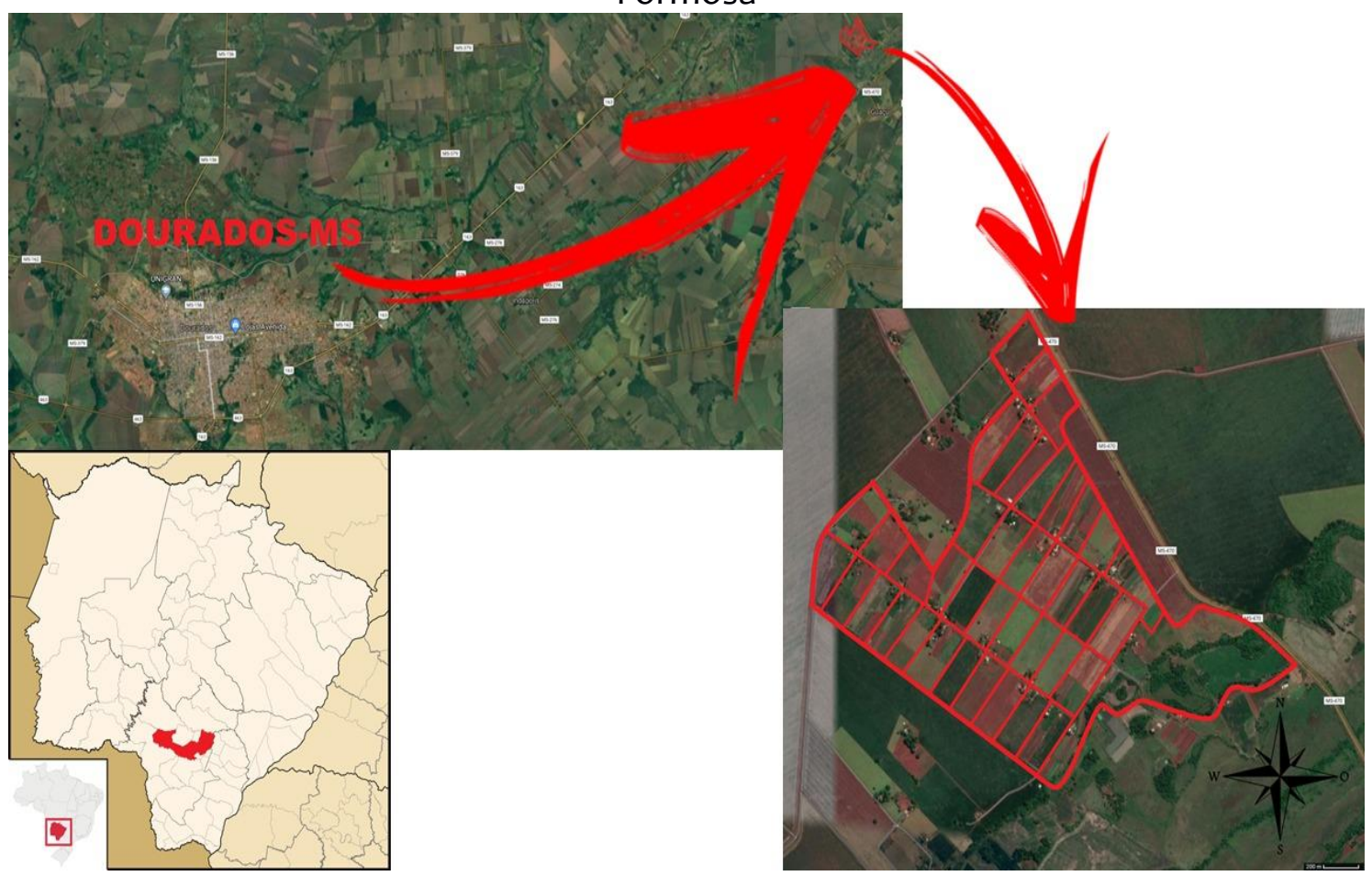

Fonte: Adpatada de IBGE, 2010 e RIBEIRO; ABREU, 2005.

Nesta seção destacam-se os procedimentos metodológicos que foram utilizados na construção deste trabalho. A metodologia desse estudo é 
caracterizada como mista (qualitativa e quantitativa), descritiva e exploratória em que foi realizado uma pesquisa de campo no segundo semestre de 2015. A aproximação do pesquisador com a área de estudo ocorreu por meio da AGÊNCIA DE DESENVOLVIMENTO AGRÁRIO E EXTENSÃO RURAL (AGRAER), que forneceu o contato de alguns produtores residentes daquela localidade, dessa forma, os pesquisadores entraram em contato com o presidente da associação (AGROFORM), para assim, agendar a coleta de dados. Logo, houveram 3 tentativas de ligação antes da autorização de agendamento para a coleta de dados.

O interesse em estudar o assentamento desse estudo ocorreu devido a proximidade a área de estudo com a zona urbana, além disse a facilidade em manter contato com os produtores, ainda, no ano de 2014 um estudo tinha sido executado naquela localizada, como parte da dissertação de mestrado de um acadêmico, porém não tinha como foco políticas públicas, logo, verificou-se a necessidade de investigar as políticas públicas que estavam em exercício no assentamento.

Posteriormente, visitou-se as propriedades no qual foram feitas entrevistas semiestruturados e aplicados questionários contendo 34 questões (abertas e fechadas) distribuídas em 3 grupos, características socioeconômicas do produtor rural, do negócio e do Programa de Aquisição de Alimentos. O questionário foi adaptado a partir de AMORIM (2014). A amostra baseou-se em 35 famílias assentadas, de um total de 46. Afim de analisar os dados se utilizou a estatística descritiva.

\section{Resultados e discussões}

Nesta seção apresentam-se os resultados referentes aos 35 lotes do assentamento Agrovila Vila Formosa que compõe a área de estudo deste trabalho, localizado no estado de Mato Grosso do Sul, na cidade de Dourados. Após a aplicação e análise dos questionários verificou-se as características socioeconômicas dos produtores rurais (Tabela 3). 
Tabela 3. Características socioeconômicas dos produtores rurais do assentamento Agrovila Vila Formosa

\begin{tabular}{|c|c|c|}
\hline Variáveis & $\mathrm{N}^{\circ}$ & $\%$ \\
\hline \multicolumn{3}{|c|}{ Gênero } \\
\hline Masculino & 23 & $65,72 \%$ \\
\hline Feminino & 12 & $34,28 \%$ \\
\hline \multicolumn{3}{|c|}{ Idade } \\
\hline $0-30$ & 3 & $8,57 \%$ \\
\hline $31-40$ & 4 & $11,43 \%$ \\
\hline $41-50$ & 7 & $20 \%$ \\
\hline Acima de 50 anos & 21 & $60 \%$ \\
\hline \multicolumn{3}{|c|}{ Escolaridade } \\
\hline Sem instrução & 3 & $8,57 \%$ \\
\hline Ensino fundamental incompleto & 19 & $54,28 \%$ \\
\hline Ensino fundamental completo & 4 & $11,43 \%$ \\
\hline Ensino médio incompleto ( $2^{\circ}$ grau $)$ & 3 & \\
\hline Ensino médio completo & & $8,57 \%$ \\
\hline Ensino superior incompleto & 2 & $5,71 \%$ \\
\hline Ensino superior completo & 3 & $8,57 \%$ \\
\hline & 1 & $2,86 \%$ \\
\hline \multicolumn{3}{|c|}{ Número de pessoas por família } \\
\hline $1-2$ pessoas & 10 & $28,57 \%$ \\
\hline 3-4 pessoas & 15 & $42,86 \%$ \\
\hline 4- 5 pessoas & 4 & $11,43 \%$ \\
\hline $5-6$ pessoas & 4 & $11,43 \%$ \\
\hline Acima de 7 pessoas & 2 & $5,71 \%$ \\
\hline \multicolumn{3}{|c|}{ Tempo de atuação na propriedade } \\
\hline Até 5 anos & 1 & $2,86 \%$ \\
\hline De 5 a 7 & 4 & $11,43 \%$ \\
\hline De 7 a 9 & 5 & $14,28 \%$ \\
\hline De 9 a 11 & 8 & $22,86 \%$ \\
\hline Acima de 11 anos & 17 & $48,57 \%$ \\
\hline \multicolumn{3}{|c|}{ Participa do Programa de Aquisição de Alimentos desde o início } \\
\hline Sim & 20 & $57,14 \%$ \\
\hline Não & 15 & $42,86 \%$ \\
\hline \multicolumn{3}{|c|}{ Já trabalhou ou trabalha fora do meio rural } \\
\hline Sim & 14 & $39 \%$ \\
\hline Não & 21 & $61 \%$ \\
\hline
\end{tabular}

Fonte: Elaborado pelos autores com base na pesquisa.

Dos 35 assentados entrevistados, 23 pertencem ao gênero masculino e 12 ao feminino, em percentual isso corresponde a 65,72 e 34,28, respectivamente. Quanto a idade, observa-se que mais de $60 \%$ possuem acima de 50 anos. Ainda, do total de entrevistados existem 3 que não possuem grau de instrução, além disso 19 (54,28\%) não completaram o ensino fundamental. $\mathrm{O}$ número de assentados que vivem nos lotes varia entre 1 e 7 indivíduos, predominando entre 3 e 4 pessoas por família. Quase metade dos assentados trabalham no campo a mais de 11 anos, essa experiência contribui para o manejo da produção. Tanto é que, $61 \%$ dos entrevistados nunca trabalharam na zona urbana, dedicando seu tempo somente a atividade rural. 
Na Tabela 2 buscou-se analisar o perfil do negócio dos assentados na Agrovila da Vila Formosa e para que isso pudesse ocorrer foram elaboradas perguntas direcionadas a comtemplar esse aspecto.

Tabela 2. Características do negócio ou empreendimento dos assentados

\begin{tabular}{|c|c|c|}
\hline Variáveis & $\mathrm{N}^{\circ}$ & $\%$ \\
\hline \multicolumn{3}{|c|}{ Faturamento mensal dos assentados antes do PAA } \\
\hline $\begin{array}{l}\text { Até } 1 \text { salário mínimo } \\
\text { Entre } 1 \text { e } 2 \text { salários mínimos } \\
\text { Entre } 3 \text { e } 4 \text { salários mínimos } \\
\text { Acima de } 5 \text { salários mínimos }\end{array}$ & $\begin{array}{l}21 \\
10 \\
3 \\
1\end{array}$ & $\begin{array}{l}61 \% \\
27,57 \% \\
8,57 \% \\
2,86 \%\end{array}$ \\
\hline \multicolumn{3}{|c|}{ Faturamento mensal dos assentados depois do PAA } \\
\hline $\begin{array}{l}\text { Até } 1 \text { salário mínimo } \\
\text { Entre } 1 \text { e } 2 \text { salários mínimos } \\
\text { Entre } 3 \text { e } 4 \text { salários mínimos } \\
\text { Acima de } 5 \text { salários mínimos }\end{array}$ & $\begin{array}{l}15 \\
7 \\
11 \\
2\end{array}$ & $\begin{array}{l}42,86 \% \\
20 \% \\
31,43 \% \\
5,71 \%\end{array}$ \\
\hline \multicolumn{3}{|c|}{ Destino da produção } \\
\hline $\begin{array}{l}\text { Feira Livre } \\
\text { Supermercados locais } \\
\text { Direto ao consumidor } \\
\text { Programas (PAA) } \\
\text { Alimentação Escolar }\end{array}$ & $\begin{array}{l}0 \\
1 \\
7 \\
22 \\
5\end{array}$ & $\begin{array}{l}0 \\
2,86 \% \\
20 \% \\
62,86 \% \\
14,28 \%\end{array}$ \\
\hline \multicolumn{3}{|c|}{ Como negocia sua produção? } \\
\hline $\begin{array}{l}\text { Diretamente e sozinho } \\
\text { Via associação e coletivamente } \\
\text { Em parceria com outro produtor }\end{array}$ & $\begin{array}{l}17 \\
15 \\
3\end{array}$ & $\begin{array}{l}48,57 \% \\
42,86 \% \\
8,57 \%\end{array}$ \\
\hline \multicolumn{3}{|c|}{ Desde a primeira distribuição de lotes você faz parte do assentamento } \\
\hline $\begin{array}{l}\text { Sim } \\
\text { Não }\end{array}$ & $\begin{array}{l}22 \\
13\end{array}$ & $\begin{array}{l}62,86 \% \\
37,14 \%\end{array}$ \\
\hline
\end{tabular}

Fonte: Elaborado pelos autores com base na pesquisa.

Neste tópico verificou-se que $62,86 \%$ dos assentados estão no local desde a primeira distribuição dos lotes. Já 37,14\% possuem terras adquiridas ou cedidas por outros que, por algum motivo, abandonaram a atividade. Cabe ressaltar que a comercialização dos lotes é proibida, mesmo assim, ilicitamente isso ocorreu. Atualmente, notou-se que o faturamento mensal depois do PAA aumentou. Por exemplo, antes do PAA 61\%, os assentados possuíam receitas de 1 salário mínimo ( $R \$ 788,00)$ mensalmente, após enquadrarem-se no PAA esse montante diminuiu para $42,86 \%$ e consequentemente houve uma ascensão no faturamento de 3 a 4 salários mínimos, antes do PAA eram apenas 3 entrevistados, após 11.

No que diz respeito a destinação da produção, 22 assentados comercializam por meio da venda direto do Programa, infelizmente apesar da existência de uma associação predomina a comercialização individual. Isso pode ser reflexo de uma dificuldade de cooperação entre os assentados, ou até mesmo preferência individual.

Um estudo elaborado por Reis (2009) assemelha-se com os dados obtidos nesta pesquisa, pois à venda também é feita individualmente, por $53 \%$ dos 
produtores, sem passar pela associação. A Agrovila Formosa, através de sua associação denominada AGROFORM, participa do PAA desde 2010. Constatamos que em 20 de janeiro de 2010, foi feito o lançamento em Dourados, do Programa de Aquisição de Alimentos da Agricultura Familiar, uma parceria da prefeitura, CONAB (Companhia Nacional de Abastecimento), e Associação de Produtores da Agrovila do distrito de Vila Formosa. A distribuição da mercadoria acontece semanalmente na sede do Banco de Alimentos Municipal. Logo após, todo o produto é encaminhado para 14 entidades, que se encarregam em distribuir às famílias cadastradas.

Depois de analisarmos as características socioeconômicas e o perfil do negócio, por fim na Tabela 3 foram abordadas questões que procuravam evidenciar a parte específica a que norteia este trabalho.

Tabela 3. Característica do Programa de Aquisição de Alimentos.

\begin{tabular}{|c|c|c|}
\hline Variáveis & $\mathrm{N}^{0}$ & $\%$ \\
\hline \multicolumn{3}{|c|}{ Como soube do PAA? } \\
\hline Órgãos públicos & 7 & $20 \%$ \\
\hline Produtor & 22 & $62,86 \%$ \\
\hline Notícias & 6 & $17,14 \%$ \\
\hline \multicolumn{3}{|c|}{ Valorização dos preços } \\
\hline Sim & 29 & $82,86 \%$ \\
\hline Não & 6 & $17,14 \%$ \\
\hline \multicolumn{3}{|c|}{ Satisfação dos preços } \\
\hline Bom & 18 & $51,43 \%$ \\
\hline Satisfatório & 17 & $48,57 \%$ \\
\hline Ruim & 0 & 0 \\
\hline \multicolumn{3}{|c|}{ Em que nível melhorou a qualidade tecnológica em relação a produção? } \\
\hline $10 \%$ a $30 \%$ & 2 & $5,71 \%$ \\
\hline $40 \%$ a $60 \%$ & 22 & $62,86 \%$ \\
\hline $70 \%$ a $100 \%$ & 11 & $31,43 \%$ \\
\hline \multicolumn{3}{|c|}{ Diversificação da produção } \\
\hline Sim & 28 & $80 \%$ \\
\hline Não & 7 & $20 \%$ \\
\hline \multicolumn{3}{|c|}{ Os produtos possuem rotulagem, selos de inspeção municipal } \\
\hline Sim & 0 & \\
\hline Não & 35 & $100 \%$ \\
\hline \multicolumn{3}{|c|}{ Importância da cooperativa para a inserção e manutenção do PAA } \\
\hline Importante & 16 & $45,72 \%$ \\
\hline Não é importante & 14 & $40 \%$ \\
\hline Indiferente & 5 & $14,28 \%$ \\
\hline
\end{tabular}

Fonte: Elaborado pelos autores com base na pesquisa.

O Programa de Aquisição de Alimentos foi criado em 2003, porém apenas em 2010 o Assentamento Agrovila Vila Formosa iniciou sua atuação no programa. A priori em diversos estudos como os de (SILIPRANDI; CINTRÃO, 2014; DELGADO, 2013; MEDEIROS et al., 2011) elencam limitações enfrentadas pelos produtores no momento de enquadra-se nesta política pública, em destaque, estão o acesso a Declaração de Aptidão ao Pronaf - DAP, problemas de vigilância sanitária como a 
posse de certificações que facilitam o poder de venda e compra dos agentes envolvidos, a falta de acesso informacional pelo poder público.

Os dados analisados neste trabalho confirmam esses fatos, uma vez que, a ciência sobre o PAA veio por meio da divulgação e interação comunicativa dos produtores, sendo apenas $20 \%$ através de órgão públicos. No que diz respeito aos preços de comercialização dos produtos, 29 produtores afirmaram que o valor se acentuou após o PAA. Tanto é que, os 35 entrevistados consideraram os preços dos produtos bom ou satisfatório, sendo que 18 correspondem a bom e 17 satisfatório.

Cada produtor pode vender por ano oito mil reais em produtos, isso faz com que o agricultor familiar aumente o volume de produção por possuir um destino final, não correndo o risco de produzir e não vender. Todavia, essa necessidade de oferta e demanda tende no aumento da utilização tecnológica, buscando a ascensão na produção, de tal forma que, o teto de compra direta pelo governo seja atingido, aumentando assim, a receita líquida familiar. O PAA também proporcionou a diversificação da produção em $80 \%$, no entanto, $100 \%$ dos produtos produzidos nos lotes não possuem selos de inspeção municipal (rotulagem).

\section{Considerações finais}

A fome e a miséria nos últimos anos tem sido tema de discussões e mobilizações na sociedade brasileira. Pensando nisso, observa-se que a intervenção governamental por meio de políticas públicas como o PAA foi uma forma de atender as necessidades básicas alimentares de pessoas carentes na sociedade brasileira, inclusive na cidade de Dourados-MS.

No entanto, considerando o cenário político atual, políticas públicas estão inexistindo, devido a sua descontinuidade em decorrência de prioridades mandatárias, inclusive o PAA enquadra-se nessas. Isso significa que, intencionalmente ou não, o governo brasileiro não tem destinado tanto capital de terceiros como em tempos anteriores, e sabe-se que o pequeno produtor rural depende de investimentos de terceiros.

De forma geral, o Programa buscou valorizar a produção e a cultura alimentar das populações, dinamizando a economia local, a formação de estoques estratégicos, a melhoria da qualidade dos produtos da agricultura familiar, o incentivo ao manejo agroecológico dos sistemas produtivos e ao resgate e preservação da biodiversidade.

A partir dos dados apresentados verificou-se que após o enquadramento do assentamento no PAA ocorreram contributos sociais e econômicos, uma vez que houve melhoria na qualidade de vida e aumento de renda, além de gerar recursos e sustentação de preços aos agricultores familiares, promovendo a segurança alimentar e nutricional das populações urbanas e rurais, sobretudo aquelas menos favorecidas. Assim, a produção de alimentos atualmente caminha junto com o pensamento na sustentabilidade, sendo assunto de grande importância social para os agricultores familiares. O foco na sustentabilidade de produção passou a ser ferramenta indispensável entre os agricultores familiares, claro que existem métricas que são capazes de auferir a sustentabilidade de fato, não é o caso desse estudo. 
De modo geral, a criação do Programa foi de grande importância, no que diz respeito à diminuição das disparidades regionais, no qual o produtor familiar detinha de uma parceria fixada com o governo federal no fornecimento de produtos para entidades governamentais e filantrópicas, contribuindo para uma melhor alimentação das populações carentes. Sugere-se para trabalhos futuros a atualização dos dados posteriores ao ano de 2015, a fim de comparar a evolução ou não do assentamento neste intervalo temporal, considerando outra política publica em execução, caso isso ocorra.

\section{REFERÊNCIAS}

AQUINO, J. R. DE; GAZOLLA, M.; SCHNEIDER, S. Dualismo no campo e desigualdades internas na agricultura familiar Brasileira. Revista de Economia e Sociologia Rural, v. 56, n. 1, p. 123-142, 2018.

ALTIERI, M.; FUNES-MONTOZOTTE, F. PETERSON, P. Agroecologically eficiente agricultural systems for smallholder farmers: contributions to food sovereignty. Agron. Sustain. Dev, v.32, p.1-13, 2012.

AMORIM, R.M. Redes de cooperação em associações de pequenos produtores: Um estudo no assentamento municipal agrovila "Vila Formosa" em Dourados - MS". 2014. Dissertação (mestrado em agronegócios) - Universidade Federal da Grande Dourados-MS, Dourados. 2014.

BARCELOS, C. O. G.; REIS, C. V. C. Os Níveis de Renda dos Assentados da Agricultura Familiar no Mato Grosso do Sul. Carta de Economia e Negócios - UCB, v.1, n. 2 e 3, 2014. BARNES, A., DE SOTO, I., EORY, V., BECK, B., BALAFOUTIS, A., SÁNCHEZ, B., VANGEYTE, J., FOUNTAS, S., VAN DER WAL, T., GÓMEZ-BARBERO, M. Influencing factors and incentives on the intention to adopt precision agricultural technologies within arable farming systems. Environmental Science and Policy, v. 93, n. September 2018, p. 66-74, 2019.

BRASIL. Brasil: 70\% dos alimentos que vão à mesa dos brasileiros são da agricultura familiar. 2017. Disponível em: http://www.mda.gov.br/sitemda/noticias/brasil-70-dosalimentos-que-v\%C3\%A30-\%C3\%Ao-mesa-dos-brasileiros-s\%C3\%A30-da-agriculturafamiliar. Acesso em: 10 de dez. 2017.

CARVALHO, G. S.; NETO, A. J. P. O programa de aquisição de alimentos no Tocantins: as condições sociais de realização de mercados com práticas de acesso individuais e coletivas. Redes (St. Cruz Sul, Online), v. 21, n. 3, p. 258 - 276, 2016.

CASTILHOS, D. S. B.; DENARDI, R. A.; HENDRIXM, E.; BIANCHINNI, V. Fatores que afetam o desenvolvimento dos pequenos municípios do Paraná. In: XXXIX

Congresso Brasileiro de Economia e Sociologia Rural, 2001. 
COLNAGO, E. T. P.; HESPANHOL, R. A. D. Da modernização da agricultura ao desenvolvimento territorial: um olhar sobre a atuação do estado brasileiro e a implantação de políticas públicas. Revista formação (online), v. 24, n. 43, p. 23-42, 2017.

CONAB. Companhia Nacional de Abastecimento. O Programa de Aquisição de Alimentos - PAA: Legislação Básica. 2012. Disponível em:

http://www.conab.gov.br/OlalaCMS/uploads/arquivos/12_07_19_16_26_55_livreto_p aa_-_dipai_versao_publico_externo_-atualizacao__-_15_marco_2012_.pdf $>$. Acesso em: 18 de ago. 2016.

CONAB. Companhia Nacional de Abastecimento. Compêndio de Estudos Conab, v. 9, 2017. Disponível em:http://www.conab.gov.br/OlalaCMS/uploads/arquivos/17_07_18_11_35_03_comp endio.pdf. Acesso em: 10. Jan. 2018.

CONAB. ACOMPANHAMENTO DA SAFRA BRASILEIRA DE GRÃOS | Quarto levantamento - 01/2016. 2015, p. 19. Disponível em: http://www.conab.gov.br/OlalaCMS/uploads/arquivos/16_01_12_09_00_46_boletim _graos_janeiro_2016.pdf. Acesso em: 02 jun. 2016.

CONAB. Companhia Nacional de Abastecimento. Perspectiva agropecuária, Brasília, v.4, p. 1-129, 2016. Disponível em:

http://www.conab.gov.br/OlalaCMS/uploads/arquivos/16_09_13_09_06_46_perspec tivas_da_agropecuaria_2016-17_digital.pdf. Acesso em:10.Jan. 2018.

DELGADO, G. C. Relatório de avaliação do PAA - III Síntese. Brasília, 2013.

DIAS, T. F.; NUNES, E.M.; TORRES, F. L.; TORRES, A.C.M. O programa de aquisição de alimentos da agricultura familiar (PAA) como estratégia de inserção socioeconômica: o caso do território da cidadania sertão do Apodi (RN). Rev. G\&DR, v. 9, n. 3, p. 100-129, 2013.

D’ ÁVILA, C. A. R.; SILVA, S. P. Segurança alimentar e desenvolvimento local: uma análise dos resultados do Programa de Aquisição de Alimentos (PAA) em Minas Gerais. Rev. Pol. Públ, v.15, n.2, p. 335-346, 2011.

DEVES, O. D.; RAMBO, A. G. Mercados institucionais e a comercialização de alimentos na agricultura familiar: o programa de aquisição de alimentos no município de São Pedro do Butiá-RS-Brasil. REDES - Rev. Des. Regional, Santa Cruz do Sul, v. 18, n. 1, p. $147-166,2013$.

FAO - Organização das Nações Unidas para a Agricultura e Alimentação (2017). The future Trends of food and and challenges. Disponível em: http://www.fao.org/3/ai6583e.pdf. Acesso em: 12. Dez. 2017. 
FAO. Organização das Nações Unidas para a Agricultura e Alimentação (2016). FAO: Se o atual ritmo de consumo continuar, em 2050 mundo precisará de 60\% mais alimentos e 40\% mais água. Disponível em: https://nacoesunidas.org/fao-se-o-atualritmo-de-consumo-continuar-em-2050-mundo-precisara-de-60-mais-alimentos-e-40mais-agua/. Acesso em: 05 out. 2017.

FOLEY, J.A., RAMANKUTTY, N., BRAUMAN, K.A., CASSIDY, E.S., GERBER, J.S., JOHNSTON, M., MUELLER, N.D., O'CONNELL, C., RAY, D.K., WEST, P.C., BALZER, C., BENNETT, E.M., CARPENTER, S.R., HILL, J., MONFREDA, C., POLASKY, S., ROCKSTRÖM, J., SHEEHAN, J., SIEBERT, S., TILMAN, D., ZAKS, D.P.M. Solutions for a cultivated planet. Nature, v. 478, n. 7369, p. 337-342, 2011.

GAZOLLA, M.; SCHNEIDER, S. Qual "fortalecimento" da agricultura familiar? Uma análise do Pronaf crédito de custeio e investimento no Rio Grande do Sul. Rev. Econ. Sociol. Rural, v. 51, n. 1, 2013.

GRISA, C.; SCHMITT, C.J.; MATTEI, L.F.; MALUF, R.S.; LEITE, S.P. Contribuições do Programa de Aquisição de Alimentos à segurança alimentar e nutricional e à criação de mercados para a agricultura familiar. Revista Agriculturas, v. 8, n. 3, p. 34-41, 2011.

GRISA, C. As redes e as instituições do Programa de Aquisição de Alimentos (PAA). Rev. G\&DR, v. 6, n. 2, p. 97-129, 2010.

HELING, C.A.; OLIVEIRA, E.R.; ALMEIDA, R.A.; ARAÚJO, A.M. MAGALHÃES, A. M.; SOUZA, A. G. PEREIRA, T. L. PROGRAMA DE AQUISIÇÃO DE ALIMENTOS EM MS: SOBERANIA ALIMENTAR, CRISE E PERSPECTIVAS DE SUPERAÇÃO. Revista online de extensão e cultura, v. 5, n. 07, 2017.

HESPANHOL, R. A. M. Programa de Aquisição de Alimentos: Limites e potencialidades de políticas de segurança alimentar para a agricultura familiar. Soc. \& Nat., v. 25, n.3, p. 469-483, 2013.

IBGE. INSTITUTO BRASILEIRO DE GEOGRAFIA ESTATÍSTICO. Indicadores IBGE Contas Nacionais Trimestrais Indicadores de Volume e Valores Correntes Outubro / Dezembro 2017. Disponível em:

https://biblioteca.ibge.gov.br/visualizacao/periodicos/2121/cnt_2017_4tri.pdf. Acesso em: 10. Jan. 2018.

IBGE. INSTITUTO BRASILEIRO DE GEOGRAFIA ESTATÍSTICO. Censo Agropecuário 2006. Disponível em:

https://biblioteca.ibge.gov.br/visualizacao/periodicos/50/agro_2006_agricultura_fa miliar.pdf. Acesso em: 10. Jan. 2018.

INCRA, 2017. Incra nos Estados - Informações gerais sobre os assentamentos da Reforma Agrária. Disponível em:

http://painel.incra.gov.br/sistemas/index.php. Acesso em: 10. Dez. 2017. 
. Lei $\mathrm{n}^{\circ} 11.326$, de 24 de julho de 2006. Estabelece as diretrizes para formulação da política nacional da agricultura familiar e empreendimentos familiares rurais. Presidência da República. Brasília/DF, 2006. Disponível em: Acesso em: 18 maio. 2016.

KUMAR, V., JAT, H.S., SHARMA, P.C., BALWINDER-SINGH, GATHALA, M.K., MALIK, R.K., KAMBOJ, B.R., YADAV, A.K., LADHA, J.K., RAMAN, A., SHARMA, D.K., MCDONALD, A. Can productivity and profitability be enhanced in intensively managed cereal systems while reducing the environmental footprint of production? Assessing sustainable intensification options in the breadbasket of India.

Agriculture, Ecosystems and Environment, v. 252, n. September 2017, p. 132-147, 2018.

MACIEL, C. A. R.; FLECH, E. M. O PROGRAMA DE AQUISIÇÃO DE ALIMENTOS E O ESTÍMULO À PRODUÇÃO ORGÂNICA. In: I congresso internacional de direito ambiental e ecologia política - UFSM - III Seminário ecologia política e direito da América Latina. p. 138-149.

MDA. MINISTÉRIO DO DESENVOLVIMENTO AGRÁRIO. Emissão de Extrato de DAP. Disponível em: < http://smap14.mda.gov.br/extratopf/PesquisaTitular.aspx> Acesso em 25 maio 2015.

MARQUES, P. E. M.; EL MOAL, M.F.; ANDRADE, A.G. PROGRAMA DE AQUISIÇÃO DE ALIMENTOS (PAA) NO ESTADO DE SÃO PAULO, v. 8, n. 1, p. 63-89, 2014.

MOTTALEB, K. A. Perception and adoption of a new agricultural technology: Evidence from a developing country. Technology in Society, v. 55, p. 126-135, 2018.

NAKUJA, T.; KERR, W. A. Food security public stockholdings and trade distortions. British food jornal, v. 120, n. 5, p. 1089-1105, 2018.

MIRANDA, D. L. R.; GOMES, B. M. A. O Programa Nacional de Aquisição de Alimentos e agricultura familiar no Vale do Ribeira, Paraná, Brasil. Sustentabilidade em Debate - Brasília, v. 8, n.1, p. 67-79, 2017.

REIS, E. A. Análise da viabilidade da formação de uma rede associativa compras como estratégia competitiva para micro e pequenas empresas indústrias metal mecânicas da região de Jaraguá do Sul (SC). 2009. P. 103. Dissertação (Mestrado em Administração). Universidade Regional de Blumenau - FURB. Blumenau, 2009.

RIBEIRO, A. F. N.; ABREU, S. Política Pública de Desenvolvimento: o projeto Agrovila "Vila Formosa" no município de Dourados-MS. In: Anais do X Encontro de

Geógrafos da América Latina - 20 a 26 de março de 2005, Universidade de São Paulo, São Paulo, 2005. 
ROCHA, J.E.; ANJOS, F.S. Agricultura familiar e os mercados institucionais: análise do programa de aquisição de alimentos (CPR-Doação) em Boa Vista Roraima. Revista NERA, v. 19, n. 31, p. 111-142, 2016.

SILIPRANDI, E.; CINTRÃO, R. As mulheres agricultoras no Programa de Aquisição de Alimentos (PAA). Segurança Alimentar e Nutricional, v. 18, n. 2, p. 12-32, 2011.

SILVESTRE, L. H. A.; CALIXTO, J. S.; RIBEIRO, A. E. M. Mercados locais e políticas públicas para a agricultura familiar: em estudo de caso no município de Minas Novas, MG. In: XLIII Congresso da Sociedade Brasileira de Economia e Sociologia Rural, 2015, Ribeirão Preto.

Congresso Sober, 2005. Disponível em: www.sober.org.br/palestra/2/767.pdf. Acesso em: 08 set.2015.

SMITH, P., M. BUSTAMANTE, AHAMMAD, H., CLARK, H., DONG, H., ELSIDDIG, E.A., HABERL, H., HARPER, R., HOUSE, J., JAFARI, M., MASERA, O., C. MBOW, N. H. RAVINDRANATH, C. W. RICE, C. ROBLEDO ABAD, A. ROMANOVSKAYA, F. SPERLING, TUBIELLO, F. Agriculture, Forestry and Other Land Use (AFOLU). Clim. Chang. Mitig. Clim. Chang. Contrib. Work. Gr. III to Fifth Assess. Rep. Intergov. Panel Clim. Chang. [EDENHOFER, O., R. PICHS-MADRUGA, Y. SOKONA, E. FARAHANI, S. KADNER, K. SEYBOTH, A. ADLER, p. 811-922, 2014.

SOUZA-ESQUEDO, V.F.S.; BERGAMASCO, S.M.P.P. Análise sobre o acesso aos programas de políticas públicas da agricultura familiar nos municípios do circuito das frutas (SP).Rev. Econ. Sociol. Rural, v. 52, n.1, p. 205-222, 2014.

VALNIER, A.; RICCI, F. Programa de Aquisição de Alimentos (PAA): uma análise comparativa nos estados de Rondônia e Acre. Campo-território: revista de geografia agrária, v. 8, n. 16, p. 198-228, 2013.

VELOSO, F. A importância do Programa de Aquisição de Alimentos para as famílias e entidades beneficiárias na região da Nova Alta Paulista. Revista Pegada, v. 18, n. 2, p. 147-176, 2017.

Adáuto de Oliveira Souza. Doutor. Universidade Federal da Grande Dourados. Professor. Rodovia Dourados Itahum, Km 12 - Unidade II. E-mail adautosouz@ufgd.edu.br.

Allison Cesar Martins Souza. Graduação. Universidade Federal da Grande Dourados. Professor. Alcides João de Souza, 1905 - Dourados-MS. E-mail allisoncesar@hotmail.com.

Gabrielli do Carmo Martinelli. Mestre. Universidade Federal da Grande Dourados. Doutoranda. Alcides João de Souza, 1905 - Dourados-MS. E-mail gabrielli_martinelli@hotmail.com. 
Como citar: SOUZA, Adáuto de Oliveira; SOUZA, Allison Cesar Martins; MARTINELLI, Gabrielli do Carmo. Os reflexos socioeconômicos do Programa de Aquisição de Alimentos: Assentamento Agrovila Vila Formosa - Dourados/MS. Redes (St. Cruz Sul, Online), Santa Cruz do Sul, v. 25, p. 1890-1908, nov. 2020. ISSN 1982-6745. doi:https://doi.org/10.17058/redes.v25i4.12963.

\section{CONTRIBUIÇÃO DE CADA AUTOR}

a. Fundamentação teórico-conceitual e problematização: Adáuto e Allison

b. Pesquisa de dados e análise estatística: Allison

c. Elaboração de figuras e tabelas: Gabrielli

d. Fotos: não possui.

e. Elaboração e redação do texto: Todos os autores

f. Seleção das referências bibliográficas: Gabrielli e Allison

Fontes de financiamento: Nenhuma. 